\title{
Proyecto de agroturismo en la comarca de Terra de Lemos (Galicia) $^{1}$
}

\author{
Xavier Simón ${ }^{\mathrm{i}}$ \\ Carmen Gil Pereiras ${ }^{i i}$ \\ Pablo Carpintero ${ }^{\mathrm{iii}}$
}

Universidade de Vigo (España)

\begin{abstract}
Resumen: El proyecto Ronsel, Plan de recuperación del Patrimonio Cultural Inmaterial de Galicia, pretende la puesta en valor y salvaguardia del Patrimonio Cultural Inmaterial (PCI) de Galicia. La complejidad de este PCI, fruto de la densidad de manifestaciones culturales de la sociedad, precisaba del establecimiento de un plan de acción que respondiese a los siguientes objetivos básicos: Identificación, documentación, investigación, protección, promoción, transmisión y difusión del Patrimonio Cultural Inmaterial. El Proyecto Ronsel sostiene que es posible definir estrategias de desarrollo socioeconómico a partir del conocimiento tradicional, mediante propuestas innovadoras que garantizando nuestra propia supervivencia, contribuyan a la conservación del contorno natural y social. El siguiente artículo, expone la iniciativa financiada por el programa (INCITE), sobre un plan piloto de creación de productos turísticos en torno al PCI.
\end{abstract}

Palabras clave: Agroturismo; Patrimonio cultural inmaterial; Productos Turísticos;Turismo de experiencias; Turismo rural.

Title: Agritourism project in Terra de Lemos (Galicia)

Abstract: The Project for the Recovery of Galician Intangible Cultural Heritage known as Ronsel Project intends to promote the reassesment and conservation of Galician Intangible Cultural Heritage or Patrimonio cultural inmaterial (PCI). The richness and complexity of heritage derived from a great variety of cultural and social expressions calls for the establishment of a wide action plan that proves capable of achieving the following basic goals: identification, documentation, research, protection, promotion, transmission and socialization of Intangible Cultural Heritage. The Ronsel Project, departs from the principle that it is possible to identify strategies of economic development based on the traditional knowledge and practices that allow for innovative ways of administering, thus contributing to guarantee the sustainable growth of the community and the conservation of its natural and social environment. The following article presents the activities financed by the INCITE program, thus offering a first assessment on designing tourism products based on intangible cultural heritage.

Keywords: Agritourism; Intangible cultural heritage; Product tourism; Rural tourism; Tourism of experience.

i Profesor titular del Departamento de Economía Aplicada de la Universidade de Vigo. E-mail: xsimon@uvigo.es ii Profesora Asociada del Departamento de Organización de Empresas y Marketing de la Universidad de Vigo. E-mail: carmengil@uvigo.es

iii Investigador contratado por el Proxecto Ronsel de la Universidad de Vigo. E-mail: pablo.carpin@gmail.com 


\section{Introducción}

El turismo desde la perspectiva antropológica es un fenómeno sociocultural complejo que posibilita a los turistas y residentes la vivencia de la alteridad, actuando como un vehículo de intercambio cultural entre personas y grupos humanos, entre nosotros y los otros; un juego de espejos entre unos y otros (Pereiro, 2009).

Los medios rurales viven desde hace años una revalorización patrimonial que no puede dejar de ser vista como una reacción social frente al desarraigo causado por la aceleración de la vida moderna, por la desertificación del campo y por la desaparición de los modos de vida tradicionales (Peixoto, 2002).

El medio rural adquiere un nuevo valor y es convertido en producto y mercancía que circula en espacios globales y que ofrece un paquete emocional que como afirma Pereiro (2009:255) proporciona "tradición", "autenticidad", "naturalidad", todos ellos considerados valores perdidos en los medios urbanos.

El espacio rural adquiere así una mayor atracción para los habitantes de las ciudades, debido a la "crisis de memoria" asociada a los procesos de globalización y a las transformaciones sociales ocurridas en el espacio y en el tiempo (Harvey, 1989).

La existencia en Galicia de una clara ruptura de la cadena de transmisión oral, tanto inter como intra generacional, convierte a una parte importante de la sociedad gallega, habitante principalmente de las villas y ciudades, en potenciales destinatarios de productos culturales resultado de la activación y puesta en valor del patrimonio cultural material e inmaterial en el espacio rural.

El presente artículo resume parte de la iniciativa financiada por el programa (INCITE) ${ }^{2}$, Proyecto de Agroturismo en la comarca Terra de Lemos, que se está desarrollando en el interior de la provincia de Lugo, (Galicia), en el período 2008-2011.

Los objetivos que persigue el proyecto son:

1. Potenciar el desarrollo turístico económico de la comarca de Terra de Lemos con base en el aprovechamiento del Patrimonio Cultural (PC) a través de productos turísticos específicamente diseñados para ese fin.

2. Contribuir a la conservación del PC de la comarca a través de su puesta en valor y difusión mediante la oferta de productos turísticos creados con base en el conocimiento tradicional de los portadores y diseña- dos para facilitar la participación, vivencia y experiencia del $\mathrm{PC}$ por parte de los potenciales visitantes.

\section{Proxecto Ronsel}

El PATEL se encuadra dentro de un proyecto más ambicioso financiado por la Xunta de Galicia a través de las Consejerías de Cultura y Medio Rural en colaboración con las universidades de A Coruña, Santiago de Compostela y Vigo: el proyecto Ronsel.

El proyecto Ronsel, coordinado por la Universidad de Vigo, operativo ya desde hace tres años, pretende la puesta en valor y salvaguarda del Patrimonio Cultural Inmaterial (PCI) de Galicia. La complejidad de este PCI, fruto de la densidad de manifestaciones culturales de la sociedad, precisó del establecimiento de un plan de acción que respondiese a los siguientes objetivos básicos: Identificación, Documentación, Investigación, Protección, Promoción, Transmisión y Difusión del PCI.

La estructura operativa del proyecto se inspira en las convenciones de la UNESCO en cuanto a la clasificación del PCI en cinco ámbitos, a saber:

1. Tradiciones y expresiones orales.

2. Artes del espectáculo.

3. Usos sociales, rituales y actos festivos.

4. Conocimientos y usos relacionados con la naturaleza y el universo.

5. Técnicas artesanales tradicionales.

Corregir la situación actual del PCI gallego reclama la coordinación entre los agentes participantes (comunidades de portadores/as, asociaciones, instituciones, particulares etc.) y una a puesta decidida por parte de las administraciones en la ejecución de acciones a largo plazo. En este sentido, una de las metas iniciales del proyecto Ronsel fue el análisis pormenorizado de la situación del PCI en cada uno de estos cinco ámbitos, tornándose fundamental contemplar a las comunidades de portadores/ as como aquellos espacios donde el patrimonio se expresa.

Por este motivo, se pretende la definición de un plano de desarrollo socioeconómico y cultural del territorio, que debe contribuir a reconstruir el tejido social que sostiene el sistema de cultura tradicional, y de esta forma adoptar soluciones de vida para las nuevas realidades sociales.

Los especialistas que trabajan en este proyecto guían su trabajo de análisis y diseño de acciones de salvaguarda y puesta en valor a través de los siguientes principios básicos:

1. El patrimonio inmaterial se salvaguarda esencialmente mediante la creatividad y su materialización por los miembros de las comunidades que lo producen y mantienen. 
2. Las acciones sobre el PCI deben facilitar, estimular y proteger el derecho y la capacidad de las comunidades a seguir interpretando su patrimonio cultural dotándose de sus propias modalidades de conservación y ordenación.

3. La cultura propia compartida y el diálogo cultural deben fomentar la creatividad general, y garantizar siempre el reconocimiento de la singularidad y los intercambios equitativos.

4. Se procura recuperar la vitalidad del PCI velando por la posibilidad de reproducir sus significados, las condiciones que lo hicieron posible y las competencias necesarias para su creación, interpretación y transmisión, tratando al mismo tiempo de no perpetuar modelos de desigualdad.

5. Se deben fundar iniciativas destinadas a proteger el PCI en principios como el respeto a los derechos humanos universalmente aceptados, la equidad y su carácter duradero y el respeto a todas las culturas que, a su vez, respetan a las demás.

\section{Patrimonio Cultural y Turismo}

El empleo de la cultura como atracción para promover el desarrollo económico en general, y el turismo en particular, se hace cada vez más evidente. Si primero fueron los centros históricos, los sitios arqueológicos y museos, ahora las ceremonias y rituales, las prácticas cotidianas como la cocina y otros usos simbólicos, son movilizados como recursos en el turismo y en la promoción de industrias centradas en el aprovechamiento del patrimonio cultural (Álvarez, 2006:2).

El turismo cultural, siguiendo a Prats y Santana (2005:16), es turismo patrimonial y el patrimonio no es la cultura, por esa razón el patrimonio puede integrarse en el mercado turístico, porque, de algún modo puede ser vendido, mientras la cultura no pode ser vendida, porque debe ser vivida.

La perspectiva productivista sobre el PC, de la que ya dieron cuenta varios autores (García Canclini, 1989; Ashwoth, 1994; Kirshenblatt-Glimblett, 2001), considera el patrimonio cultural como un recurso para el turismo cultural y para otras actividades económicas.

Bajo una concepción mercantilista, el patrimonio se interpreta que debe satisfacer el consumo contemporáneo.

Las nuevas corrientes en la gestión del patrimonio optan por la dinamización buscando además de la necesaria conservación, rentabilidad y beneficios. El patrimonio, trasciende lo puramente cultural y se transforma en un potencial recurso económico.

Transformar los recursos en productos y ofertas tu- rísticas es la meta que persiguen los planificadores y entes de gestión turística de los destinos. Será necesario pues analizar la posible aplicabilidad del patrimonio cultural en la oferta de productos capaces de satisfacer las necesidades de los turistas, habida cuenta de la complejidad y fragilidad intrínseca de esta tipología de recursos.

Esta interpretación del patrimonio, se aúna con una visión patrimonialista y participacionista que Pereiro (2006 ) expone:

a.) Patrimonialista: El patrimonio cultural es la recuperación del pasado a partir de una perspectiva del presente, para explicar el cambio en los modos de vida. Estaría integrado por elementos culturales que adquieren un nuevo valor a través de un proceso de patrimonialización. Es una intervención en la cultura.

b.) Participacionista: Entiende el patrimonio cultural y su preservación en relación a las necesidades globales de la sociedad y con un proceso democrático de selección de lo que se conserva. Ligada a la participación social, con el objeto de evitar la monumentalización y cosificación de los objetos. Resalta el hecho de pensar primero en las personas y después en los bienes culturales.

Santana (2003:33), sostiene que la tendencia de la demanda determinó la oferta de nuevos productos turísticos que pueden encuadrarse en dos grandes bloques estrechamente vinculados, medio ambiente físico (la naturaleza) y medio ambiente cultural (patrimonial-identitario). Según este mismo autor, el turismo alternativo intenta conseguir una experiencia de lo auténtico a través de la naturaleza, la cultura, la gente o una combinación de las mismas.

Es necesario matizar que el concepto de autenticidad es una creación individual (Santana, 2000:4), que es contextualizada según las experiencias de cada sujeto. Todas las culturas son en cierto sentido inauténticas ya que son inventadas, recreadas, fabricadas y reconstruidas durante transformaciones sociales permanentes (Pearce y Moscardó, 1986).

El turismo cultural es una forma de turismo donde la cultura, en su materialidad o inmaterialidad (costumbres, tradiciones...) es el factor principal de atracción en el viaje (Roldán, 2004:21), pero hay que tener en cuenta que la sola presencia de los atractivos patrimoniales no implica la existencia de productos turísticos, siendo necesario un proceso de organización e inversión para su correcta puesta en uso (Grande Ibarra, 2001).

Cuando en el sector turístico hablamos de crear un producto turístico cultural, nos referimos a la organización técnica de los recursos culturales de un destino con 
el objetivo de que puedan ser conocidos y disfrutados por los visitantes (López López, 2005).

Los recursos, son los elementos base sobre los que se desarrolla la actividad turística; son aquellos atractivos que pueden generar o suscitar el interés del visitante y determinar y motivar el desplazamiento a un determinado destino. Sin recursos no hay producto turístico, pero los recursos turísticos no bastan para construir productos.

El punto de partida son los recursos, el conjunto de atractivos del territorio. Según Chías (2004) el hombre, el legado histórico y su contorno, configuran los tres elementos base para la gestión turística. El producto turístico, se puede definir entonces como la suma de recursos que se estructuran para el uso y disfrute turístico.

Desde la disciplina del marketing turístico, un producto cultural sería aquel recurso cultural en el que se pueden realizar una o varias actividades (visitar, asistir, participar, comer, comprar, etc.) porque está formulada una propuesta de accesibilidad (temporal, espacial y/o económica) de un público al mismo (Chías, 2004:10).

La palabra producto aplicada al patrimonio provoca, muchas veces, rechazo. En este mundo global no atrae lo semejante ni la imitación, sino lo propio, lo que nos diferencia y nos particulariza (Kapszuk, 2006). Un buen producto es aquel que no solo cuida el patrimonio, sino que genera lazos de continuidad de ese patrimonio con base en los valores que transmite.

El patrimonio puede ocupar lugares muy diversos respecto a los productos turísticos, desde ser el motivo de compra principal, hasta mero escenario, pasando por todo tipo de valores añadidos (tangibles o intangibles), puede servir para enriquecer la oferta, crear imagen, reorientar el posicionamiento, desestacionalizar si interesa, pero para eso, debe entenderse y aceptar su dimensión lúdica y trabajar activamente para conjugarla imaginativamente con su dignidad (Prats, 2003:135).

En la actualidad, adquiere cada vez más importancia el turismo experiencial o emocional. Richards (2004) afirma que el turismo cultural está convirtiéndose en un producto de vivencia en el que la visita se juzga en función de todas las características del lugar y no solo por su valor cultural. En esta línea, los visitantes buscan cada vez más una experiencia total que incluya ocio, cultura, educación e interacción social (De Rojas y Camarero, 2008).

En turismo no se venden realmente productos, sino que se venden experiencias (Vogeler y Hernández 2002). El turista que busca experiencias es aquel que quiere evadirse, descubrir, disfrutar y conectar con la gente del lugar y con sus costumbres; más que comprar paquetes turísticos, se compran historias para vivir y para contar. Las experiencias son aquellas vivencias, sentimientos, sensaciones, que nos fascinan e impactan y que precisamente por ello se convierten en memorables (Bordas, 2003:2).

Frente a la madurez de productos convencionales, el mercado propone formas de turismo alternativas. Así, se presentan ofertas diversificadas donde recursos ligados a la naturaleza, la cultura y el patrimonio pasan a tener un papel relevante en la experiencia de ocio.

El turismo cultural y el turismo rural intentan satisfacer una demanda cada vez más exigente y segmentada que, entre otras tendencias, manifiesta un claro interés por aprender, interpretar y conocer mejor el entorno al que se viaja. La OMT (Organización Mundial del Turismo) en su documento Turismo Panorama 2020 señalaba las tendencias de nuevos segmentos de mercado que demandaban productos y servicios renovados, basados especialmente en el espectáculo, la emoción y la educación.

De acuerdo con los postulados anteriores, el plan estratégico del turismo de España, Plan Horizonte 2020 (Secretaría General de Turismo, 2007), subraya y reafirma entre sus claves estas ideas, siendo uno de sus ejes principales la creación de valor al cliente a través de experiencias turísticas que diferencien y potencien la personalidad de los destinos turísticos.

\section{Turismo en el espacio rural en Galicia: el agrotu- rismo, una opción a potenciar.}

El turismo rural recibe este calificativo cuando se inscribe geográficamente en el espacio rural existen múltiples definiciones y no hay un consenso a la hora de definirlo. El factor clave a tener en cuenta es el medio de acogida, el entorno o medio rural.

Valdés (1995) da una definición generalista de turismo rural como aquella actividad turística que se desarrolla en medio rural y cuya motivación principal es la búsqueda de atractivos asociados al descanso, paisaje, cultura tradicional y que huye de la masificación.

La Comisión de las Comunidades Europeas, definió turismo rural como aquella actividad turística, realizada en medio rural, compuesta por una oferta integrada de ocio, dirigida a una demanda cuya motivación es el contacto con el entorno autóctono y que tenga una interrelación con la sociedad local (Crosby, 1993).

Según Canoves Herrera y Villarino (2005:67), el concepto de turismo rural manejado por la OMT, que se resume en la figura 1, comprendería una red de relaciones entre cuatro grandes áreas: campo, patrimonio, vida rural y actividades.

Crosby y Prato (2009:24-25) explican que hoy en día 
la estructura del mercado está sobre-segmentada y eso se traduce en la existencia de diferentes motivaciones a la hora de elegir la oferta turística rural. Así surgen una amplia variedad de conceptos como turismo de naturaleza, ecoturismo, turismo ecológico, agroturismo, turismo verde, pasando por combinaciones como ecoetno-agroturismo, bio-turismo, campo-eco turismo, etc.
Se puede decir que el turismo rural en Galicia está en un momento de transición, o incluso en el cierre de un ciclo donde se consiguieron objetivos en cuanto a creación de infraestructura turística de alojamiento, pero donde continúan a ser patentes ciertos defectos. En este sentido, hace falta ser capaces de hacer del turismo una actividad generadora de desarrollo, y eso se

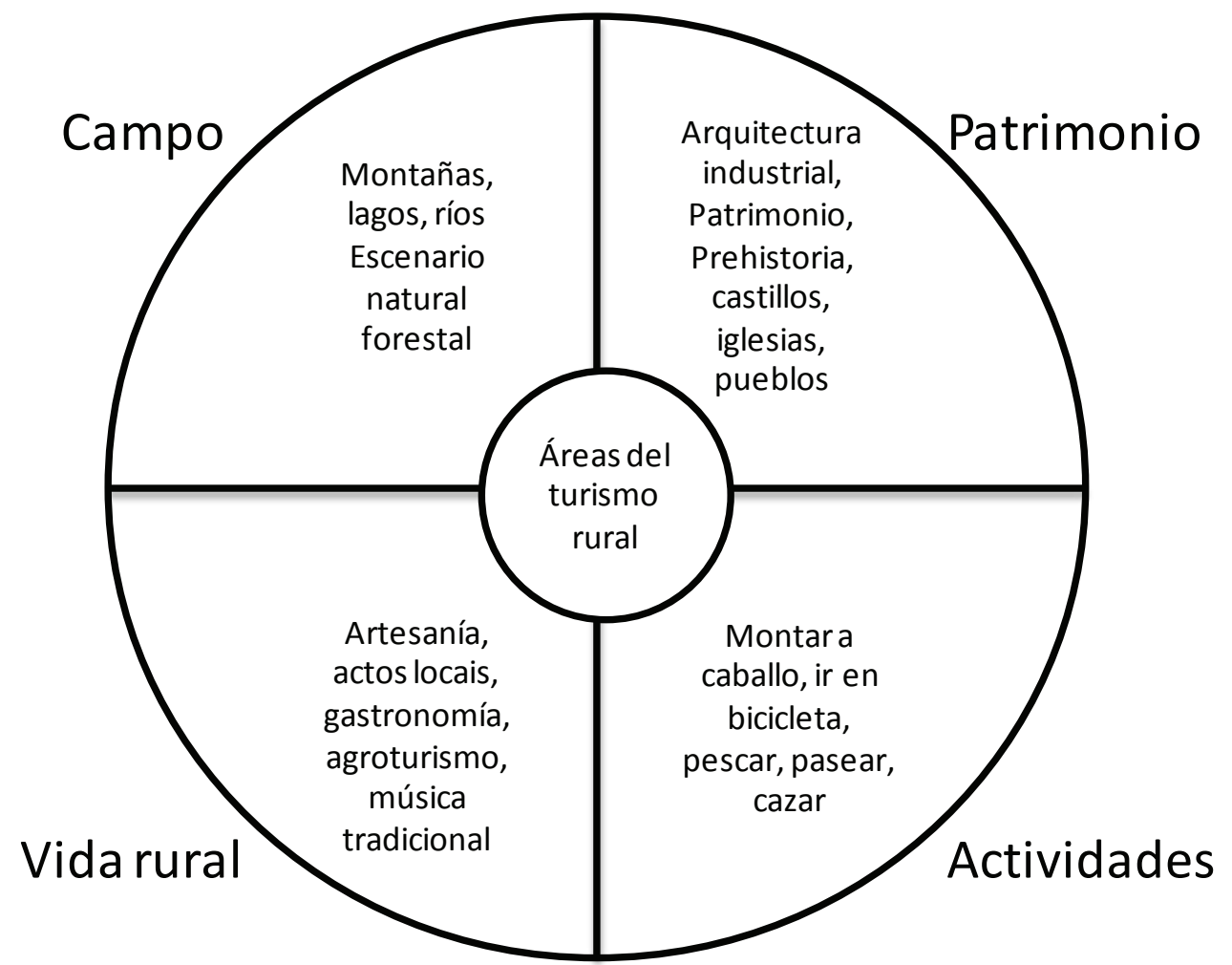

Figura 1: Áreas de turismo rural según la OMT. Fuente: Cánoves, Herrera y Villarino (2005:67) sobre OMT.

El concepto de turismo rural puede interpretarse de una manera muy amplia. Blanquer (2000:606), llama la atención sobre el enfoque unidimensional que adoptan la mayoría de las Comunidades Autónomas en España, centrado en la ordenación de los servicios de alojamiento, pero desconectado de otras políticas públicas cómo conservación del entorno natural, desarrollo y/o recuperación de la artesanía y el folclore tradicional, etc.

El turismo rural debiera entenderse de manera amplia, pero en la práctica se observa cierto peligro de entenderlo tan sólo como una actividad definida por un tipo de alojamiento (Sparrer 2007). La misma idea es corroborada por Besteiro (2006) que manifiesta la necesidad de ofertar un producto en el que, aparte del alojamiento, se incluya el disfrute de diferentes actividades en el medio rural que permitan la prolongación de la temporada alta. consigue ayudando a recuperar y poner en valor el patrimonio material e inmaterial, y dinamizando la economía agrícola y artesanal de forma que complemente a la turística (Lois, 2007:10).

Uno de los objetivos que se persiguen en la actualidad es crear productos turísticos integrales en el destino. La administración gallega apunta que deben reorientarse los fondos públicos para la creación de servicios complementarios y atractivos que atraigan a más visitantes y que aumenten su estancia media; servicios relacionados con deportes en la naturaleza, rutas gastronómicas, con productos culturales del territorio y con servicios de ocio.
En esta línea, Pereiro (2009) opina que la calidad turística de una zona no depende solo del alojamiento, sino también de las actividades que pueden realizar los turistas; subrayando que el gran reto para el turismo en el espacio rural es diseñar productos turísticos completos: alojamiento, alimentación y recreación. Además del alojamiento, la nueva demanda turística necesita realizar un cierto tipo de actividades deportivas y culturales. El espacio rural, sin duda, cada vez se vende más como un neoproduto para el consumo turístico (Pereiro y Prado, 2005). La sociedad no rural está más interesada que nunca en los espacios rurales para vivir y para el ocio. El espacio rural intenta responder a las demandas de una nueva sociedad post industrial que contempla la naturaleza como valor y como bien estético, que mira al rural por ser un espacio con valía residencial y por su valor como marco para actividades de ocio y descanso 
(Cabana 2008). Los turistas que eligen el espacio rural tienen en mente romper con la formalidad de sus comportamientos en la ciudad; son turistas que valora la calidad de vida y que buscan emplazamientos tranquilos, con naturaleza viva y cultura local atractiva (García Henche, 2005).

Santana (2000) distingue dos tipologías de turistas rurales: unos interesados por el entomo físico y las actividades deportivo-recreativas que se pueden llevara cabo en él, y otros atraídos por la cultura local propiamente dicha. Cabrini (2002) afirma que un factor importante en la elección del turista tiene que ver con la cultura rural, pues el turismo rural abarca un conjunto de actividades donde la cultura rural es un componente c lave del produc to ofertado. Lo c Unioso, explica Cabana (2008:25), es que ese modo de vida que ya no existe, es justamente lo que los neorurales se empeñan en imitar, lo que los turistas rurales quieren sentir durante un fin de semana al año y lo que, a pesar de todo, marca aún la identidad del país.

\section{Agroturismo}

El concepto de agroturismo, término que empleamos en este proyecto, está sujeto a diversas interpretaciones que trataremos de abordar.

Según Toppan (2005:313), cultura, viaje y campo, son conceptos que provienen de un mismo marco de referencia: del campo vienen todas las palabras que tienen sentido de cultura.

Sus rasgos diferenciales, se encuentran vinculados a la presencia de la naturaleza que se expresa, en la mayoría de los casos, bajo la forma de paisaje cultivado. El contacto permanente que tiene el habitante rural con la naturaleza, influyó y determinó su modo de vida, su sistema de valores, tradiciones y creencias como también se tradujo en sus realizaciones materiales y en su patrimonio arquitectónico, representado en viviendas, monumentos, caminos, etc.

El agroturismo puede ser considerado como un segmento incluido en el turismo rural, una modalidad de turismo en áreas rurales que incluye el alojamiento, la alimentación y actividades agropecuarias que ofrecen al turista productos naturales locales para su alimentación.

Para Weaver y Fennel (1997:357), son empresas rurales que aúnan el trabajo en las explotaciones agrarias con el turismo. Hoy en día, actividades como las denominadas U-Pick o Pick-your-Own Operations están de moda en países como Estados Unidos, Canadá o Gran Bretaña. Bajo la idea de "recoléctalo tu mismo, págalo y llévatelo a casa", se fomenta una forma de venta di- recta de productos frescos en el mismo espacio donde se cultivan, abonando un precio justo y sin intermediarios. Las iniciativas en este campo en Galicia aún están por desarrollarse.

Existe acuerdo en que el agroturismo es un tipo de turismo basado en el alojamiento en casas rurales y donde el usuario puede participar y/o observar las tareas cotidianas del lugar: agrícolas, ganaderas o artesanales. El agroturismo como modalidad de oferta turística, posibilita la oferta de actividades relacionadas con el mundo agrario y rural. Los componentes básicos de las ofertas de agroturismo son, según Adam (2004:2): "tener algo para que los visitantes vean, algo que puedan hacer y algo que puedan comprar".

Según Accueil Paysan, Federación de Agroturismo creada en Francia, la Fundación Ecoagroturismo contempla el turismo como factor de desarrollo económico y social, promoviendo la interrelación entre una agricultura sostenible y un turismo solidario, convirtiendo a los agricultores en actores de su propio desarrollo y fomentando iniciativas que luchen contra la desertización de las áreas rurales. Esta fundación considera que el agroturismo debe integrase en una estructura familiar combinada con actividades, agrarias, ganaderas o artesanas; ofertar productos caseros y/o la posibilidad de realizar actividades didácticas, de animación y/o demostración relacionadas con los recursos y oficios de la explotación, etc.

Según la catalogación actual de los establecimientos de turismo rural en Galicia, la modalidad que se entendería exclusivamente como agroturismo sería la denominada cómo grupo C, es decir, casas de labranza donde se desarrollan actividades agropecuarias en las que pueden participar los clientes alojados.

El concepto de agroturismo adoptado en este proyecto, parte de una interpretación integrada del espacio rural en el que las viviendas de turismo rural, independientemente de que sean o no explotaciones agropecuarias, puedan ofertar o relacionar a sus huéspedes con productores y actividades culturales tradicionales de la comarca, tratando de tejer redes de cooperación y sinergias en el entorno entre actividades agrarias, ganaderas, artesanales y culturales.

\section{Metodología del proyecto.}

La secuencia para el diseño de los productos turísticos fue la siguiente:

\section{Establecimiento de las bases teónicas, diseño del proyecto de agroturismo y elección del área para desamollarlo.}

El PATEL se enmarca dentro de un proyecto más ambicioso financiado también por la Xunta de Galicia a través de las Consejerías de Cultura y Medio Rural en colaboración con las universidades de A Coruña, Santia- 
go de Compostela y Vigo: el proyecto Ronsel. Los presupuestos teóricos de este proyecto, mencionados anteriormente, formaron la base del Proyecto de Agroturismo en Terra de Lemos.

En cuanto a la selección del área de estudio, la comarca de Terra de Lemos se sitúa en el sur de la provincia de Lugo (Galicia). Pertenecen a esta comarca los siguientes ayuntamientos: Bóveda, Monforte de Lemos, Pantón, A Pobra de Brollón, O Saviñao y Sober. Posee una extensión aproximada de 940,4 Km2 y una población de algo más de 34.800 habitantes.

Uno de los principales atractivos de la comarca, y su principal seña de identidad, es la Ribeira Sacra, conocida por sus tesoros naturales y biológicos, constituyendo un vastísimo ecosistema de gran variedad y riqueza, así como un paisaje único. El curso de los ríos Miño y Sil, discurre encajado entre montañas de pendientes verticales formando los cañones del Miño y Sil, con una altitud media de 500 a $700 \mathrm{~m}$, dibujando un paisaje espectacular.

Para la selección del área se tuvieron en cuenta varios aspectos:

1. Estado del patrimonio.

Se procuró un área con una riqueza patrimonial suficientemente atractiva desde todos los puntos de vista. Un área de interior con un rico patrimonio natural y que mostrara también un patrimonio monumental y arqueológico de cierta importancia. Por otra parte, buscamos una zona en la que el PCI fuera escasamente conocido y por tanto atractivo para los potenciales turistas.

2.Accesibilidad de la zona.

Procuramos un área fácilmente accesible desde diversos lugares de Galicia, con buenas comunicaciones con el exterior y unas infraestructuras adecuadas.

3.Desarrollo rural.

Preferimos áreas pobremente desarrolladas o en vías de hacerlo, procurando que el impacto del proyecto fuese substancial.

Después de analizadas estas variables, la comarca de Terra de Lemos cumplía todos los criterios de selección. Disfruta de un patrimonio natural muy diverso, rico y bien conservado, en el que se mezcla el más destacable entorno de ribera fluvial de Galicia, junto con otro montañoso que da entrada a una de las zonas de alta montaña más conocidas de Galicia: O Courel.

Por otra parte, esta zona aúna uno de los patrimonios monumentales más ricos de Galicia, con cerca de cuarenta iglesias románicas entre las que se hallan cinco monumentos nacionales, con otras edificaciones civiles destacadas, además de poseer un abundante y desconocido patrimonio arqueológico con numerosos restos megalíticos (petroglifos y túmulos), castreños y romanos (villas y explotaciones mineras).

En lo referente al PCI, la zona muestra una riqueza semejante al resto de la Galicia interior. En los últimos años alguna de sus manifestaciones más singulares como son los Carnavales Ribeiraos y el del Oso de Salcedo están siendo objeto de una mayor divulgación y puesta en valor, sin embargo el resto de las manifestaciones del PCI se encuentran pobremente estudiadas en comparación con otras áreas gallegas.

Por lo que respecta a la accesibilidad de la zona, su situación central en Galicia, así como las nuevas carreteras que la comunican con Ourense, Lugo y Santiago hacen esta comarca accesible desde cualquier lugar de Galicia en aproximadamente una hora. Por otra parte, Monforte contiene uno de los nudos ferroviarios más importantes de Galicia. Por último, la comarca de Terra de Lemos es conocida por su pobre desarrollo rural, fruto del abandono de las aldeas que Galicia viene sufriendo en los últimos años y que comienza a afectar a la propia capital de la comarca.

\section{Estudio pormenorizado del estado del PC en Tena de Lemos.}

El estudio se realizó en varias fases. La primera se basó en un primer contacto con las instituciones que ya habían trabajado sobre el tema en esta comarca. De este modo, se inició una colaboración con el Centro de Desarrollo Comarcal que nos facilitó los primeros materiales bibliográficos, fundamentalmente guías turísticas, libros, artículos periodísticos, que nos permitieron establecer un plan de trabajo de campo para cubrir las lagunas existentes y ahondar en los datos ya conocidos.

En turismo el conocimiento de los recursos es el paso previo al diseño de actividades turísticas. Identificar los atractivos turísticos es uno de los procesos necesarios en la etapa de diagnóstico de un proceso de planificación turística. El instrumento que se emplea para realizar dicha identificación es el inventario de recursos turísticos.

Existen varias metodologías para la realización de inventarios de recursos turísticos (Leno Cerro,1993). Puesto que este proyecto se basa en el PC, estudiamos tres aspectos fundamentales para realizar el inventario: el patrimonio natural, el material y el inmaterial, elaborándose un completo informe sobre su situación actual y posibilidades como generadores de riqueza turística.

\section{Contacto con los agentes sociales implicados: ca- sas de turismo nural, tejido asoc iativo, explotaciones agranias, comunidades de montes y particulares.}

Después de analizado el estado del patrimonio y sus posibilidades desde el punto de vista turístico, comenzó un proceso de contacto con los agentes implicados en la recreación del patrimonio y con las 
instalaciones turísticas de la zona para ver la posibilidad de desarrollar productos turísticos concretos.

Desde el PATEL buscamos productores agrícolas, vitivinícolas y ganaderos interesados en participar en el proyecto que cumplieran con la premisa de mantener las prácticas tradicionales de producción, o bien que hicieran esta de forma ecológica. De este modo se contactó con productores de castañas, uva, vino, fruta y criadores de cerdo celta, diseñándose productos que tuvieran en cuenta estas prácticas.

Se mantuvieron conversaciones y reuniones con todo el tejido asociativo de la zona, de suerte que se explicaron los objetivos del proyecto a las asociaciones culturales implicadas en el Carnaval Ribeirao y en el del Oso de Salcedo; y se hizo lo propio con la asociación O Colado do Vento, centrada en la recuperación de leyendas y otras tradiciones de la comarca, y con las dos asociaciones micológicas de la zona, diseñándose productos específicos en colaboración con ellas.

Las casas de turismo rural, que concentran la mayor parte de la oferta turística de la zona se agrupan en la asociación, LUGOSUR, con la que el PATEL contactó y se reunió para ver las posibilidades de organizar actividades conjuntas.

\section{Contac to con las instituciones administrativas.}

Una vez explicados los objetivos del proyecto y puestos de acuerdo asociaciones y productores en las líneas básicas a seguir en el diseño de los productos, el PATEL contactó con las instituciones de la zona para intentar obtener el apoyo económico para la contratación de dos guías turísticos que el propio proyecto no podía asumir. Para eso, se presentó a los ayuntamientos un plan piloto con los productos turísticos ya diseñados. Este mismo proyecto fue presentado a la Diputación Provincial de Lugo junto con un plan de negocio en el que se estimaba la viabilidad del proyecto. También se contactó con el Obispado de Lugo para intentar buscar una solución a los problemas existentes de accesibilidad en las visitas a las iglesias románicas de la comarca.

De esta forma el PATEL tejió una compleja red en la que se implicó a particulares, artesanos, asociaciones culturales y turísticas, e instituciones políticas y eclesiásticas en el desarrollo de un proyecto de agroturismo experiencial.

\section{Diseño de los productos tuństicos.}

Para el diseño de los productos que el PATEL ofrecería al largo del año 2010 se tuvieron en cuenta los dos estudios previos existentes sobre el turismo de la zona: Estudio de Mercado en Destino Turístico: Ribeira Sacra elaborado por Fraiz Brea (2007) para la Ribeira Sacra y el Estudio de mercado en Destino Turístico 2008: Ribeira Sacra, del mismo autor (2008). Estos informes incluyen los datos recogidos mediante encuestas en todos los ayuntamientos que pertenecen a la zona denominada Ribeira Sacra. Puesto que la mayor parte de la comarca de Terra de Lemos está contenida dentro de esta área, consideramos estos resultados como extrapolables a la comarca que nos ocupa.

El perfil demográfico mayoritario del visitante corresponde con un trabajador cualificado, sin cualificar o funcionario, residente en Galicia y de entre 18 y 49 años de edad. Los turistas procedentes de Galicia representan un $46 \%$, y los que vienen de fuera de España tan sólo un 5.5\%.

Considerando sólo los turistas que hacen noche en la zona, la estancia media es de 3.28 días, siendo mayoritarias las estancias de entre 1 y 3 días (56.2\%). Las actividades mayoritarias son pasear (90.6\%), salir a comer (73.9\%) y realizar visitas culturales (57\%).

Las recomendaciones que se extraen de los estudios de Fraiz Brea $(2007,2008)$ son:

- Crear paquetes y rutas turísticas que amplíen la oferta complementaria y tengan un efecto positivo en la estancia, número de pernoctas y gasto del visitante.

-Diseñar y ejecutar campañas promocionales propias y en cooperación con Turgalicia para captar turistas y excursionistas, residentes en zonas relativamente próximas, de fin de semana y puentes, y para posicionarse como un destino turístico de interior paisajístico y cultural.

-Captar visitantes en los principales puntos turísticos de Galicia (costa, Santiago de Compostela etc.) para que se acerquen a conocer la riqueza natural y el patrimonio de la Ribeira Sacra.

-Atraer colectivos específicos de turistas (viajes culturales del IMSERSO, asociaciones, visitas escolares, campamentos juveniles, etc.) ofreciendo programas turísticos adaptados.

-Mejorar la oferta de actividades deportivas en la naturaleza, aprovechando el gran potencial de la Ribeira Sacra (senderismo, pesca, equitación, cicloturismo, piragüismo, etc.)

-Promocionar las ferias gastronómicas y de artesanía de la zona.

-Mejorar la dotación de alojamientos idóneos para turistas jóvenes con menos recursos, como campings o albergues.

-Aprovechar y fomentar el producto turístico vitivinícola, mediante la cooperación con las bodegas de la Denominación de Origen Ribeira Sacra.

-Continuar mejorando la coordinación entre las oficinas de información de toda la zona para potenciar la in- 
formación turística.

-Mejorar las infraestructuras de acceso a los recursos y productos turísticos, así como la señalización y paneles explicativos.

-Mejorar las opciones de transporte colectivo en la zona, estudiando posibles combinaciones entre diferentes dicionales (miel, vino, aguardiente, cerdo, castañas, fruta etc.) poniendo al visitante en íntimo contacto con ellos.

Aquí se desarrollaron dos fórmulas para conseguir un precio del producto más bajo del habitual:

- Canjear el trabajo del visitante por una rebaja en el

medios (catamarán, tren y autobús) que permitan diversas rutas turísticas por la zona.

-Formación específica en creación de empresas y productos turísticos para la generación de emprendedores y fijación de la población.

En estos informes destaca la valoración que hacen los turistas de las actividades culturales y espectáculos: los que las valoran positivamente ascienden desde el $45 \%$ en el año 2006 al $70 \%$ en el 2008, mientras que los que la valoran negativamente descienden del $20 \%$ en el 2006 al $10 \%$ en el 2008. Sobre

\begin{tabular}{|c|c|}
\hline $\begin{array}{l}\text { PATRIMONIO } \\
\text { NATURAL }\end{array}$ & $\begin{array}{l}\text { - Rutas y senderos. } \\
\text { - Bosques. } \\
\text { - Puesta en valor de nuevas rutas, asociadas al patrimonio arqueológico, } \\
\text { geológico y otro tipo de saberes patrimoniales, como leyendas y cuentos; } \\
\text { Actividades micológicas, etc. }\end{array}$ \\
\hline $\begin{array}{l}\text { PATRIMONIO } \\
\text { MATERIAL }\end{array}$ & -Monumental: El románico. \\
\hline $\begin{array}{l}\text { PATRIMONIO } \\
\text { INMATERIAL }\end{array}$ & $\begin{array}{l}\text { - Oficios tradicionales: Alfarería de Gundivós, apicultores, aguardenteros } \\
\text { y viticultores. } \\
\text { - Los carnavales Ribeirao y del Oso de Salcedo. } \\
\text { - Prácticas patrimoniales como los magostos, vendimias, mallas, } \\
\text { matanzas, etc. } \\
\text { - Producción ecológica de productos agroalimentarios como vino, miel, } \\
\text { castañas, aguardiente, fruta etc. }\end{array}$ \\
\hline
\end{tabular}

este extremo los propietarios de las casas de turismo rural entrevistados por el PATEL continúan percibiendo un interés creciente en la demanda de actividades culturales entre sus clientes.

Con este estado de la cuestión, los objetivos principales de los productos turísticos diseñados por el PATEL serían, en relación a la oferta turística:

1. Incrementar la oferta cultural de la zona ofreciendo unos productos basados en el PC que complementen la oferta cultural ya existente.

2. Ofrecer al visitante un turismo experiencial, participativo, que permita una vivencia directa del PCI gallego y que pueda incluir formación especializada en determinados aspectos (alfarería, agricultura ecológica, música etc.)

3. Contribuir a fidelizar a los turistas ofertando actividades que se desarrollen de manera cíclica a lo largo del año y que se repitan año tras año.

En relación con los productores de la zona implicados en el proyecto:

1. Ofertar a los turistas la posibilidad de participar en los trabajos de explotación, cultivo, cuidado, etc. con algunos productos diseñados específicamente para aprender las técnicas del cultivo tradicional y/o ecológico.

2. Intentar incrementar las ventas de los productos tra-
Tabla 1: Recursos patrimoniales seleccionados para la planificación de produtos turísticos. Elaboración propia.

precio final.

- Ofertar la posibilidad de apadrinar árboles, vides y colmenas.

Después de analizados los recursos de la zona concluimos que los principales recursos patrimoniales sobre los que se planificarían los productos a ofertar serían los relacionados en la Tabla 1.

Habida cuenta de los objetivos y recursos existentes, así como de las demandas de los propietarios de las casas de turismo rural y de las asociaciones culturales de la zona, se diseñaron once productos diferentes :

1. Hace mil años

Para poner en valor el patrimonio románico y medieval de la comarca se diseñó un producto que consiste en rutas organizadas que permitirán visitar, acompañado de un guía, las principales construcciones medievales de la comarca. Se pretende una visión moderna y particularista de este patrimonio que se obtendrá mediante la contratación de un guía altamente especializado en románico y en su conexión con el PCI de la comarca. El románico es la parte central, pero también se contemplan visitas a los castillos de Monforte y Masid.

Se diseñaron cinco rutas que incluyen los cinco monumentos nacionales de la comarca. 


\section{Como las abejas}

La Ribeira Sacra es un lugar rico en explotaciones de miel, incluso en las zonas más norteñas abundaron antaño las albarizas, construcciones que protegían a las colmenas del ataque de los animales. Este producto se desarrollaría entre las albarizas de A Pobra ubicadas en Forgas, Parada de Montes, Paramedela y Loureiro y una explotación ecológica de miel en Castro de Gundivós (Sober).

La explotación ofrecerá la posibilidad de alquilar una colmena al visitante (o grupo de visitantes) a cambio de una asignación anual y de la colaboración de los visitantes en los trabajos de extracción de la miel. Durante las visitas los turistas recibirán una charla sobre las abejas por un miembro de la Asociación Gallega de Apicultores (AGA) y podrán trabajar directamente con las abejas, para ello el PATEL suministrará a la explotación 10 trajes de apicultor.

\section{Alquimistas por un día.}

Se trata de un producto relacionado con una de las principales actividades productivas de la comarca: el ciclo del vino. Se pretende que el participante entre en contacto con las técnicas de cuidado de las vides, con la vendimia y la obtención del aguardiente. Durante varios fines de semana al año se oferta la posibilidad de participar en la obtención de aguardiente por destilación artesanal. Los visitantes podrán apadrinar vides obteniendo sus productos, vino y aguardiente, a un precio inferior al del mercado. Una vez al año se ofertará también la posibilidad de participar en una vendimia tradicional. Dentro de este mismo producto se incluyen rutas de senderismo por los antiguos caminos de explotación del vino, explicaciones a pie de viña sobre la manera de cultivar el vino en la Ribeira Sacra y una visita al Ecomuseo de Arxeriz para ver las herramientas y útiles tradicionales del trabajo de los viticultores.

\section{Ruta del cerdo}

En la parte norte de la comarca se encuentran varias explotaciones dedicadas a la cría de la raza autóctona de cerdo gallego, el denominado cerdo celta.

Este producto pretende, en combinación con una de estas explotaciones, que el turista pueda comprar un cerdo celta convertido en producto final, para lo cual se habilitará dentro de la página web del PATEL un espacio para anunciar esta oferta. También se ofertará la posibilidad de participar en los trabajos de preparación de los mismos, matanza fundamentalmente, para lo cual la cooperativa de Goo junto con los vecinos de esta aldea organizarán dos matanzas anuales con la posibilidad de que los turistas participen en ellas. Las casas de turismo rural implicadas en este producto ofertarán menús gastronómicos basados en la carne de cerdo.

\section{Fuego y barro}

Mediante este producto ofertaremos la posibilidad de acercarse al conocimiento de la alfarería tradicional en Gundivós desde dos perspectivas, una didáctica y otra práctica. Se contará con la participación de los dos talleres de Gundivós. La oferta formativa consiste en cuatro fines de semana consecutivos en los que se dará un cursillo intensivo de alfarería en rueda baja, llevando al visitante desde la recogida y preparación del barro en las barreras, hasta el cocido de las piezas en el horno. La oferta didáctica es únicamente de un fin de semana y consiste en la visita a los talleres donde los turistas recibirán explicaciones y podrán manejar el barro.

6. Castañas asadas

Este producto se ofrecerá en el tiempo de recoger las castañas en los sotos del norte de la comarca y posibilitará que el visitante coja sus castañas pagándolas a precio de producción, permitiendo también la posibilidad de apadrinar un castaño y llevarse las castañas a un precio reducido a cambio de su recolección. Se programan también cinco magostos a lo largo del año en cinco casas de turismo rural diferentes que incluirán animación musical.

\section{Máscaras!}

En coordinación con las asociaciones culturales encargadas de los dos carnavales tradicionales de la zona, este producto consiste en dos fines de semana en los que se oferta la posibilidad de participar y experimentar en primera persona los carnavales Ribeirao y el de Salcedo. El turista acudiría un fin de semana unas semanas antes del carnaval para preparar su máscara y su participación en el carnaval como un vecino más, corriendo el día del carnaval junto con las máscaras propias de cada zona.

8. Carne de carbón

Un producto desarrollado en coordinación con las dos asociaciones micológicas de la zona que organizan, una vez al año, sendas jornadas micológicas. Se oferta a los visitantes: rutas por el monte acompañados de un guía especializado para reconocer las especies, participación en las jornadas micológicas y la degustación de menús a base de hongos en tres casas de turismo rural de la comarca.

9. Noches de Xacias.

Esta actividad consiste en fines de semana en los que se programan rutas que visitan los petroglifos y lugares con leyendas asociadas acompañados de un guía que explicaría los seres míticos de las aguas y los montes, así como las leyendas asociadas a los lugares a visitar. Como complemento a las visitas diurnas, por las noches se ofrecerá una sesión de cuentacuentos en las casas de turismo rural que participan. 
10. Aliméntate con sentido

Se trata de un producto diseñado para formar a los visitantes en los procedimientos de la agricultura ecológica. Está pensado como un curso de cuatro fines de semana a desarrollar en una casa de turismo rural que presta su huerta para emplearla en los trabajos de cultivo. Durante tres fines de semana al año se oferta la posibilidad de visitar una explotación ecológica de fruta para aprender a hacer diferentes membrillos y mermeladas, con la posibilidad de recoger uno mismo la fruta y comprarla a un precio menor al del mercado.

11. Bailar y tocar.

Este producto consiste en un ciclo formativo de cuatro fines de semana que acaban en un gran evento festivo que se organizará en Monforte de Lemos. Dos fines de semana consecutivos se dedican a impartir cursos de baile tradicional gallego, el tercero aúna rutas por el monte y la orilla del río con la factura de instrumentos musicales sencillos a partir de materiales vegetales. En el cuarto fin de semana se organiza una gran fiesta tradicional.

Todos los productos se encuentran detallados en http://agroturismoterradelemos.gl

\section{Puesta en marcha de los productos.}

El PATEL pretende desarrollar esta oferta turística al largo de todo el año 2010 con una programación que abarca prácticamente todos los fines de semana del año.

Para la comercialización de los productos se prevén cuatro acciones:

1. Elaboración de una plataforma digital para dar publicidad y explicar los productos. Esta plataforma permite la contratación de los servicios, la reserva online de los mismos y la contratación del alojamiento en las correspondientes casas.

2. Edición de folletos publicitarios que se repartirán en las casas de turismo rural y en las oficinas de turismo rural.

3. Inclusión de la oferta en la página web de Turgalicia.

4. Realizar campañas de publicidad a través de la web dirigidas a colectivos que puedan estar específicamente interesados en algunos de los productos.

\section{Evaluación de los resultados}

La oferta de los productos turísticos se pondrá en marcha como experiencia piloto a principios del año 2010. Para la evaluación de los resultados de esta experiencia se diseñaron dos encuestas diferentes, destinadas una a la oferta y otra a la demanda. La primera con el objeto de conocer el perfil sociodemográfico, motivaciones y grado de satisfacción de los clientes que con- sumieron los productos diseñados. La segunda pretende evaluar el grado de satisfacción de las casas de turismo rural con las actividades y productos desarrollados y observar el potencial incremento en la ocupación sufrido como consecuencia de la puesta en marcha de los productos.

También se evaluará cualitativamente, mediante entrevistas en profundidad, la opinión y evaluación que los portadores, participantes y productores tuvieron sobre esta experiencia de agroturismo.

\section{Bibliografia}

Adam, K.

2004 "Entertainment Farming and Agri-tourism". Business management guide. ATTRA. Disponible en http://attra.ncat.org/attra-pub/PDF/entertn.pdf

Álvarez, M.

2006 "Cultura y Turismo", en I Congreso Argentino de Cultura. Disponible en www. congresodecultura. com.ar. Fecha de consulta. Enero 2008.

Ashwoth

1994 "From History to Heritage - From Heritage to Identity", en: Gregory Ashworth e Peter Larkham (orgs.), Building a New Heritage. Londres, Routledge, pp. 13-30.

Besteiro, B.

2006 "El turismo rural en Galicia. Análisis de su evolución en la última década".Cuadernos de Turismo, 17: 25-49.

Blanquer, D.

2000 "Régimen jurídico del turismo rural" en Blanquer Criado, D. (dir.):" Turismo 1999. II Congreso Universidad y Empresa”, Tirant Lo Blanch, Valencia, pp 601-640.

Bordas, E.

2003 "Hacia el turismo de la sociedad de ensueño: nuevas necesidades de mercado". Disponible UOC. htttp://www.uoc.edu/dt/20219/index.

Cabana, A.

2008 "Tres tempos nun só tempo. As aldeas en Galiza. Arraianos. A vida nas aldeas $N^{\circ}$ VII, Xaneiro, pp 1926.

Cabrini, L.

2002 "Turismo, desarrollo rural y sostenibilidad" presentación en VII Congreso AECIT, Jaén 21 e 22 Outubro.

Cánoves Valiente, G., Herrera Jiménez L. y Villarino Pérez M.

2005 "Turismo rural en España: paisajes y usuarios, nuevos usos y nuevas visiones", Cuadernos de Turismo , 15: 63-76. 
Chías, J.

2004 El negocio de la felicidad. Desarrollo de Marketing turístico de Países, regiones, ciudades y lugares. Prentice Hall. Madrid.

Crosby, A.

1993 El desarrollo turístico sostenible en el medio rural. CEFAT Centro Europeo de Formación Ambiental y Turística. Madrid.

Crosby, A. y Prato, N.

2009 "Fundamentos y retos del turismo rural". en Crosby, (ed.) Re-inventando el turismo rural. Gestión $y$ desarrollo. Laertes, Barcelona. pp. 21-49.

De Rojas, C. y Camarero, C.

2008 "Visitors experience, mood and satisfaction in a heritage context: Evidence from an interpretation center". Tourism management 29: 525-537.

Fraiz Brea, J. A. et al.

2007 Estudio de Mercado en destino turístico 2007: Ribeira Sacra. Facultade de CC. EE. e turismo. Campus Universitario de Ourense. Universidade de Vigo, 2007.

2008 Estudio de Mercado en destino turístico 2008: Ribeira Sacra. Facultade de CC. EE. e turismo. Campus Universitario de Ourense. Universidade de Vigo, 2008.

García Canclini

1989 Las culturas populares en el capitalismo. México: Nueva Imagen.

García Henche, B.

2005 "Características diferenciales del Producto Turismo Rural”. Cuadernos de Turismo, 15: 113-133.

Grande Ibarra, J.

2001 "Análisis de la Oferta de Turismo Cultural en España." Estudios Turísticos 150: 15-40.

Harvey, D.

1989 The condition of Posmodernity, Oxford, Blackwell. Kapszuk, E.

2006 "Turismo y cultura", en I Congreso Argentino de Cultura. Disponible en www. congresodecultura. com.ar. Fecha de consulta 20/01/2008

Kirshenblatt-Glimblett, B.

2001 "La cultura de les destinations: teoritzar el patrimoni”, Revista de Etnologia de Catalunya, 14: 44-61.

Leno Cerro, F.

1993 Técnicas de evaluación del potencial turístico. Ministerio de Industria, Comercio y Turismo. Secretaría General de Turismo/Turespaña. Dirección General de Política Turística. Serie de Libros sobre Turismo $\mathrm{N}^{\circ}$ 2. Madrid

Lois González, R.C.

2007 "A nova política para o turismo nos espazos rurais de Galicia" en I Seminario Internacional de Turismo
Rural realidade e perspectivas do turismo nos espazos rurais. Xunta de Galicia, pp. 7-19.

López López, A.

2005 "Oportunidades para el Turismo Cultural" en De Azcárate, T. ( coord.), Dialogo sobre Turismo, Diversidad Cultural y Desarrollo Sostenible, Instituto de Turismo Responsable. Forum Barcelona, Barcelona, pp. 253-262.

Pearce, P.L. y Moscardo, G.M.

1986 "The concept of authenticity in tourists' experiences". Australian and New Zealand Journal of Socio$\log y, 22:$ 121-132.

Peixoto, $\mathrm{P}$.

2002 "Os meios rural e a descoberta do património". Oficina do Centro de Estudos Sociais CES, 75: 1-18.

Pereiro, X. y Prado, S.

2005 "Turismo e oferta gastronómica na comarca da Ulloa (Galiza): Análise de uma experiencia de desenvolvimento local". Pasos, Revista de Turismo y Patrimonio Cultural, 3(1): 109-123. (www.pasosonline. org)

Pereiro, X.

2006 "Património Cultural: o casamento entre património e cultura". ADRA N ${ }^{\circ}$ 2. Revista dos sócios do $\mathrm{Mu}$ seo do Povo Galego pp 23-41.

2009 Turismo Cultural: Uma visião antropologica. Colección PASOS edita $\mathrm{n}^{\circ} 2$. Asociación Canaria de Antropología PASOS, Revista de Turismo y Patromonio Cultural. El Sauzal, Tenerife.Disponible en www. pasosonline.org .

Prats, Ll.

2003 "Patrimonio + turismo = ¿desarrollo?". Pasos. Revista de Turismo y Patrimonio Cultural, 1(2): 127136.

Prats, LL. y Santana, A.

2005 "Reflexiones libérrimas sobre patrimonio turísmo y sus confusas relaciones". En Santana A. y Prats Ll. (coords) El encuentro del turismo con el patrimonio cultural: concepciones teóricas y modelos de aplicación. Fundación el Monte, Federación de Asociaciones de Antropología del Estado Español, Asociación Andaluza de Antropología Sevilla, pp 9-25

Richards, G.

2004 “iNuevos caminos para el turismo cultural?". En Interacció 2004. Centro de Estudios Culturales CERC, Barcelona pp1-15 disponible en www.diba.es/ cerc/arxinterac04/arcem1/richards/dipbarcelona

Roldán Martín A.

2004 "El Turismo Cultural: naturaleza y líneas de actuación", en $6^{\circ}$ congreso de turismo Universidad y Empresa. Turismo Cultural e Urbano. Tirant Lo Blanch.Valencia, pp 21-40. 
Santana Talavera, A.

2000 "Lo rural como producto turístico.¿Algo nuevo bri-

lla bajo el sol" , disponible en http://www.antropo-

logiasocial.org/contenidos/tutoriales/anttur/textos/ ATexto12.htm

2003 "Turismo Cultural, culturas turísticas". Horizontes Antropolóxicos, 20: 31-56.

Secretaría General de Turismo

2007 Turismo 2020. Plan del Turismo Español Horizonte 2020- Plan del Turismo español 0812. Documento ejecutivo. Ministerio de Industria, turismo y comercio.

Sparrer, M.

2007 Turismo no espazo rural e desenvolvemento. Estudo comparativo da provincia da Coruña e o Landkreis Wittmund. Xunta de Galicia.

Toppan, R.

2005 "Cultura y turismo como facetas de una estrategia de valorización del mundo rural en el marco de la economía del intangible y de las emociones" en De Azcárate, T (coord.) Dialogo sobre Turismo y Diversidad Cultural y Desarrollo Sostenible, Instituto de Turismo Responsable, Forum Barcelona 2004, Barcelona, pp 312-319.

Valdés Peláez ,L.

1995 "El turismo en la Unión Europea" Papers de Turisme, 17:.13-23.

Vogeler C. y Hernández E.

2002 El Mercado Turístico: estructura, operaciones y procesos de producción. Centro de estudios Ramón Areces, Madrid.

Weaver, D.B. y Fennell, D.A

1997 The vacation farm sector in Saskatchewan: a profile of operations. Tourism Management, 18: 357-365

\section{NOTAS}

1. Este trabajo es fruto de la financiación de la Dirección Xeral de I+D+i da Xunta de Galicia al Proyecto de investigación "O uso do patrimonio cultural inmaterial como factor de desenvolvemento e innovación turística: agroturismo e turismo cultural participativo" (Código 08TUR001300PR)

2. INCITE (innovación, ciencia y tecnología). Programa sectorial. Investigación aplicada e I+D. Tecnología sectorial: Turismo. Consellería de Innovación e Industria.
Recibido:

$09 / 02 / 10$

Reenviado:

$04 / 02 / 11$

Aceptado:

$10 / 02 / 11$ 